\title{
VELOCITY OF SOLID PARTICLES ENTRAINED WITH REDUCED-PRESSURE AIR FLOW IN HORIZONTAL DUCT
}

\author{
Tsuyoshi MUNAKATA, AKIRA MATSUDA, \\ NOBUYUKI HIRAI, NOBUKAZU TO AND RYUICHI KAKIHARA \\ Department of Chemical Engineering, Kyushu University, \\ Fukuoka 812
}

\begin{abstract}
The velocity of glass beads entrained with air flow in a horizontal square duct was measured in a range of pressures: $760-1 \mathrm{mmHg}, u_{\alpha}: 10,18 \mathrm{~m} / \mathrm{sec}, d_{p}: 81.5-184$ microns, $D: 2.45 \mathrm{~cm}$. It is pointed out that with respect to the flow regions in duct and around particle the present experimental conditions are considerably different from those in previous works at atmospheric pressure. Data obtained under reduced pressure are correlated within $\pm 30 \%$ by the following equation, which includes the Cumningham correction coefficient $\mathbf{C m}$.

$$
\left(\boldsymbol{u}_{a}-\boldsymbol{u}_{p}\right) / \boldsymbol{u}_{a}=1.22 \mathrm{Cm} \boldsymbol{d}_{p} \boldsymbol{u}_{a}^{0.4}
$$

$\boldsymbol{u}_{\alpha}=$ air velocity $[\mathrm{cm} / \mathrm{sec}], \boldsymbol{u}_{p}=$ particle velocity $[\mathrm{cm} / \mathrm{sec}], \boldsymbol{d}_{p}=$ particle diameter $[\mathrm{cm}]$.
\end{abstract}

\section{Introduction}

Previously the authors studied experimentally the characteristics of cyclone separators under vacuum operation and showed that fluid does not swirl in a cyclone at less than about $10 \mathrm{mmHg}$, and that separation by centrifugal force cannot be expected ${ }^{6,7}$. In such circumstances separation by inertial force will be favorable. In advance of further investigation on this subject, experiments have been made to examine the behavior of solid particles entrained with reducedpressure air flow. That is, the velocity of glass beads in a horizontal straight duct was measured by a photographic technique in a range of pressures from 760 to $1 \mathrm{mmHg}$. In this paper, the experimental conditions and results are compared with those of several previous works at atmospheric pressure, and characteristics under vacuum are discussed. Also, an empirical equation for slip velocity of particles under reduced pressure is obtained.

\section{Experimental Apparatus and Procedure}

The apparatus is shown schematically in Fig. 1. The conveying line consisted of a square glass duct $4 \mathrm{~m}$ in length and $2.45 \mathrm{~cm}$ on a side. The crosssectional area at the feed point was contracted by a venturi (6) so that particles might attain the final velocity within a shorter distance. Photographic

Received February 3, 1977. Correspondence concerning this article should be addressed to A. Matsuda. N. Hirai is now with Taiyo Furnace Constructing Co., Ltd., Fukuoka 812. N. To is at Nogata Industrial Research Institute (Fuknoka Prefecture), Nogata 822. R. Kakihara is now with Teijin Co., Ltd., Matsuyama 791-41. equipment for measurement of particle velocity could travel along the conveying line and was used at four points $0.35 \mathrm{~m}, 1.75 \mathrm{~m}, 2.65 \mathrm{~m}$ and $3.5 \mathrm{~m}$ distant from the feed point. Particles were injected into the conveying duct by a screw feeder (4), and an orifice (5) was also used to make the feed rate even. Wet-gas meters and a quadrant nozzle were used to measure the air flow rate. Particles entrained with air flow were photographed with the help of a strobolight and were collected by a cyclone (8) and a bag filter (10). Air was exhausted from the system by a vacuum pump (13) (pumping speed $1600 \mathrm{l} / \mathrm{min}$ ) through a buffer tank (11) $(490 l)$. Pressure and air flow rate were controlled by a leak nozzle (12) and a valve (2) placed immediately behind the flow meter (1). In the case of $760 \mathrm{mmHg}$, however, air was exhausted by a centrifugal blower installed immediately behind the cyclone.

Before injecting particles into the conveying duct the pressure drop for air alone was measured and the result agreed well with the existing equations on friction factor. Pressure drop for solid-air stream was little different from that for air alone because particle feed rate had to be kept small, from 0.03 to $0.13 \mathrm{~g} / \mathrm{sec}$, for the purpose of photographing the particles. The photographic technique used and the method to calculate particle velocity were the same as those of Konno et $a l^{4}{ }^{4}$. The luminescence time interval of the strobolight was varied from 250 to 500 microseconds according to pressures and air velocities. Four hundred particle velocities were calculated from about ten frames and their average value was adopted as particle velocity. 


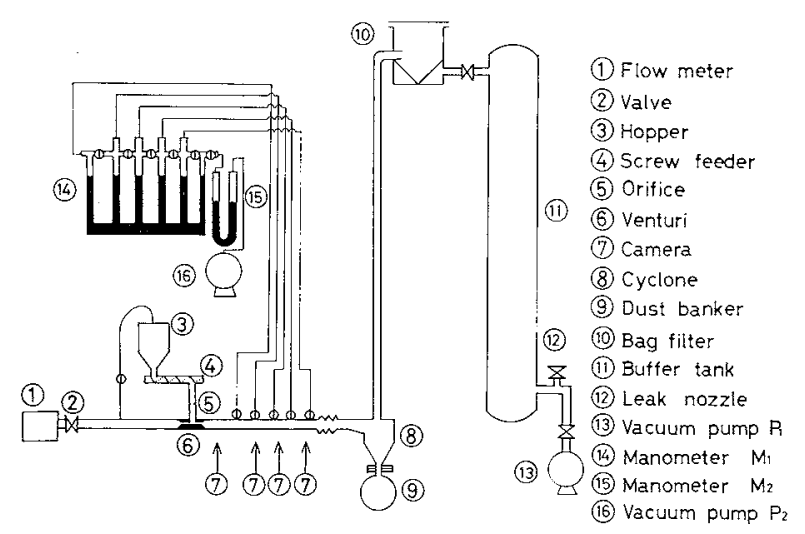

Fig. 1 Schematic diagram of experimental apparatus

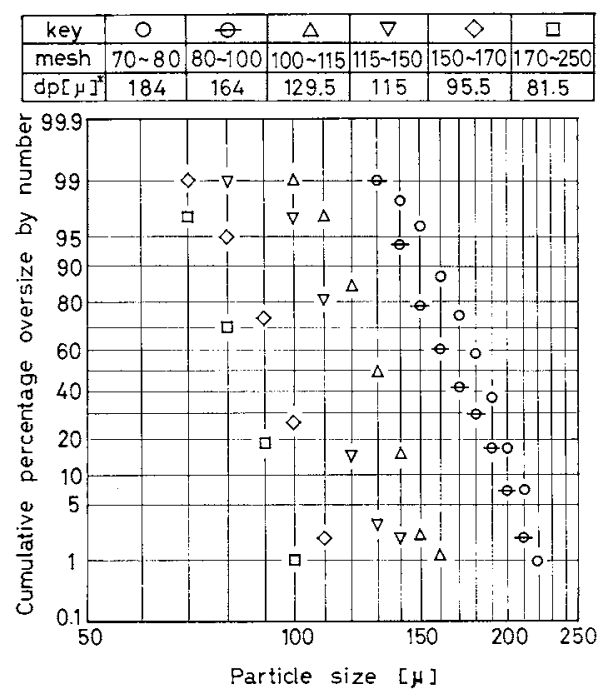

(* fifty percent particle diameter)

Fig. 2 Particle size distribution

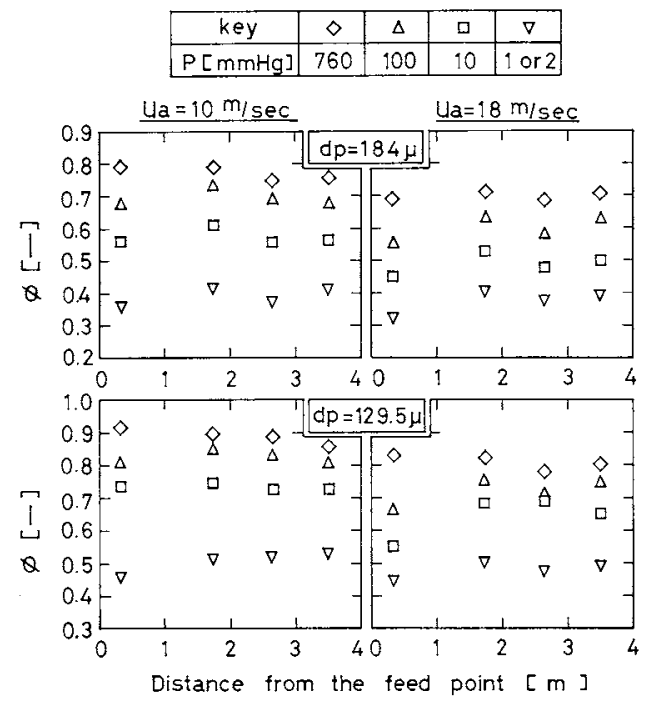

Fig. 3 Effect of particle acceleration length on velocity ratio

The solid particles used in this experiment were glass beads (density $2.48 \mathrm{~g} / \mathrm{cm}^{3}$ ), sieved by Tyler standard screens into six groups. The sizes were determined under a microscope and the distributions are shown in Fig. 2. Fifty percent particle diameter based on number of each group was adopted as the representative diameter. Air velocities of 10 and $18 \mathrm{~m} / \mathrm{sec}$ and pressures of $760,100,50,10$ and $1 \mathrm{mmHg}$ (at air velocity $10 \mathrm{~m} / \mathrm{sec}$ ) or $2 \mathrm{mmHg}$ (at $18 \mathrm{~m} / \mathrm{sec}$ because of the shortage of pumping capacity of the vacuum pump at $1 \mathrm{mmHg}$ ) were adopted as the experimental conditions.

The extent to which particle velocity was developed was estimated from the variation of the ratio of particle to average air velocity, $\phi$, at the four locations along the conveying line. Figure 3 shows the results for larger particles. Particle velocity seems to be almost developed at the point $3.5 \mathrm{~m}$ distant from the feed point. Similar results were obtained for smaller particles too. The acceleration length thus was considered to be sufficient.

\section{Discussion of Experimental Ranges}

There have been numerous studies of particle velocity under atmospheric pressure. Among them some empirical equations for the slip ratio, $1-\phi$, are shown in Table 1 together with that of the present work. The experimental ranges of particle Knudsen number and duct Knudsen number are shown in Fig. 4. With respect to flow around the particle, data at 10,2 and $1 \mathrm{mmHg}$ in the present work extend from the slip-flow region to the transition-flow region, though all data in the previous works and those at 760,100 and $50 \mathrm{mmHg}$ in the present work are in the continuum-flow region.

Figure 5 also shows the ranges of duct Reynolds number and particle Reynolds number. Particle Reynolds number is based on the observed relative velocity $\left(u_{a}-u_{p}\right)$. In the previous works flow in the duct was turbulent and flow around the particle was from Allen to Newton region. On the other hand, in the present work flow in the duct is mainly from transitional to laminar flow and flow around the particle is from Stokes to Allen region. The present data obtained at atmospheric pressure are near the experimental range of Konno et al.

\section{Experimental Results and Discussion}

3. 1 Discussion of the experimental results at atmospheric pressure

The present data at atmospheric pressure were compared with the equation of Konno et al. and the slip ratio of the present work was greater than that of Konno et al. The reason for this discrepancy is not obvious, but it is pointed out that the slip ratio of Konno et al. is rather small in comparison with those of other workers. Also, it may be due to a difference in the conveying line used, since Konno et al. used round pipes and the authors used a square duct. 
Table 1 Empirical equations of slip velocity of particle

\begin{tabular}{ll}
\multicolumn{1}{c}{ Worker } & \multicolumn{1}{c}{ Equation } \\
\hline Gasterstädt $^{2)}$ & $1-\phi=\left(0.0117+0.178 / u_{a}\right) u_{t}$ \\
Hinkle $^{3)}$ & $1-\phi=0.507 d_{p}^{0.3} \rho_{p}^{0.5}$ \\
Konno $^{4)}$ & $1-\phi=1.35 \times 10^{5}\left(u_{t} / \sqrt{g D}\right)^{0.85} / D$ \\
Present work & $1-\phi=1.22 C m d_{p} u_{a}^{0.4}$ \\
\hline
\end{tabular}

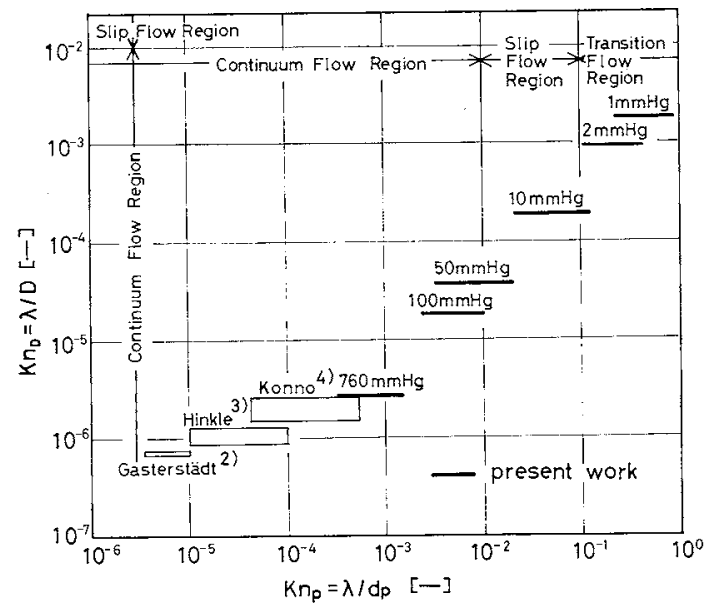

Fig. 4 Comparison of experimental ranges classified by $K n_{D}$ and $K n_{p}$

\section{2 Distribution of particle velocity in duct}

The duct was divided into four sections vertically and velocity ratios, $\phi$, in each section were calculated. The results are shown in Fig. 6. Velocity distribution of small particles is more convex than that of large particles. No inclination is apparent for either upside or downside particle velocity to be greater than the other.

\section{3 Effect of pressure on slip ratio}

The relations between slip ratio and pressure at air velocity 10 and $18 \mathrm{~m} / \mathrm{sec}$ are shown in Fig. 7 . The slip ratio increases with decreasing pressure. Flow in the duct was turbulent at atmospheric pressure and laminar below $100 \mathrm{mmHg}$ (see Fig. 4). Therefore it seems that the experimental results at atmospheric pressure cannot be simply compared with those under reduted pressure. Further, below $100 \mathrm{mmHg}$ flow around the particle is almost in the Stokes flow region (see Fig. 5). Hence the effect of pressure on slip ratio was studied for the data in a range of pressures where flow in the duct is laminar and flow around the particle in Stokes flow region. The values of slip ratio at 100 and $50 \mathrm{mmHg}$ in Fig. 7 are almost equal. On the contrary, slip ratio increases as pressure decreases from 50 to $1 \mathrm{mmHg}$. Here the values of the Cunningham correction coefficient $\mathrm{Cm}(\mathrm{Cm}=1+$ $\left.2 K n_{p}\left\{1.23+0.41 \exp \left(-0.44 / K n_{p}\right)\right\}\right)$ for the particle drag coefficient were $1.006-1.015$ at $100 \mathrm{mmHg}, 1.013-1.03$ at $50 \mathrm{mmHg}, 1.065-1.148$ at $10 \mathrm{mmHg}$ and $1.693-$ 2.729 at $1 \mathrm{mmHg}$. Accordingly, the experimental

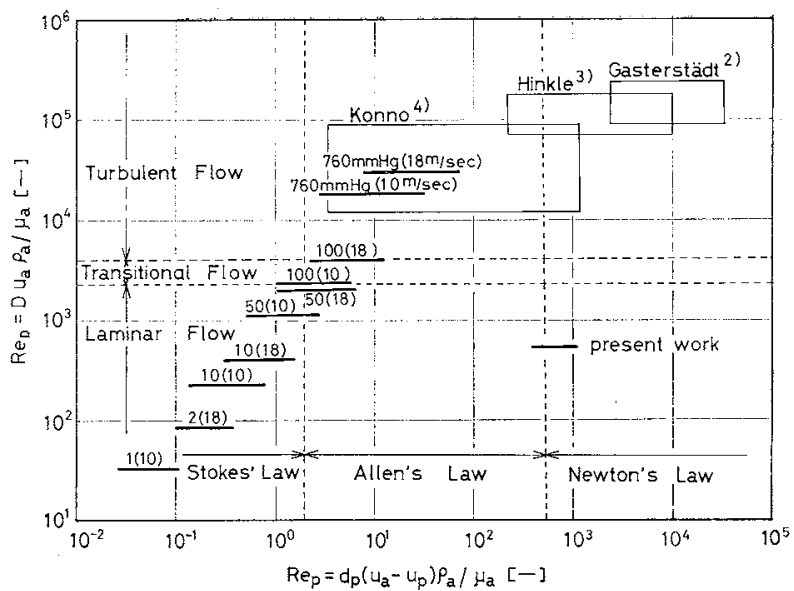

Fig. 5 Comparison of experimental ranges classified by $\boldsymbol{R} \boldsymbol{e}_{D}$ and $\boldsymbol{R} \boldsymbol{e}_{p}$

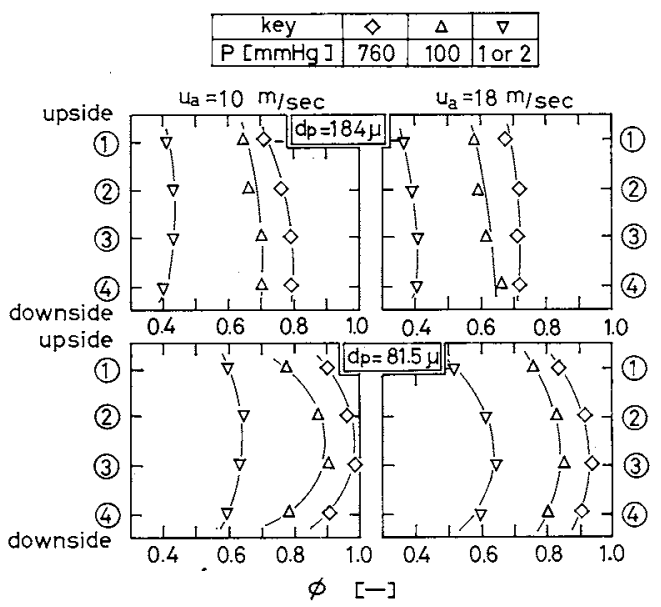

Fig. 6 Particle velocity distribution in horizontal duct

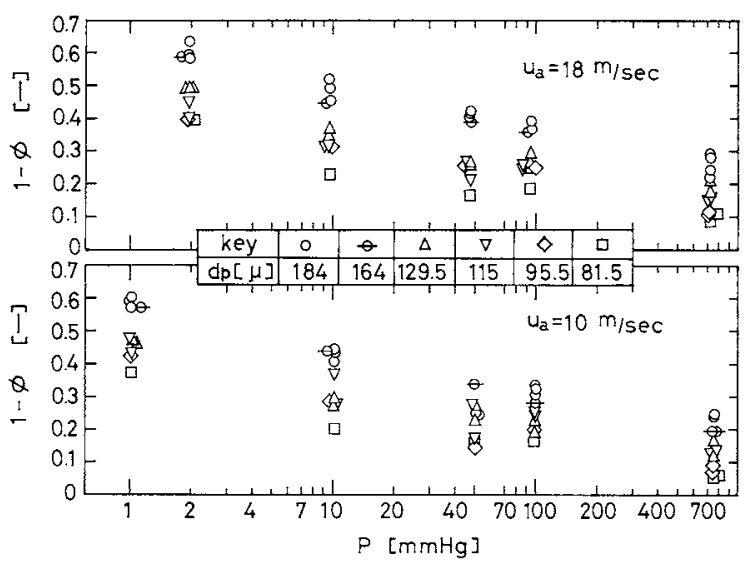

Fig. 7 Effect of pressure on slip ratio

results mentioned above can be explained as follows. Since values of $\mathrm{Cm}$ are nearly unity at 100 and 50 $\mathrm{mmHg}$, no effect of pressure appears in Fig. 7. On the other hand, as they are apparently more than unity at 10 and $1 \mathrm{mmHg}$, the effect of pressure does appear. Hence the relation between the Cunningham correction coefficient and slip ratio will be discussed.

In the present work the ratio of mean distance be- 


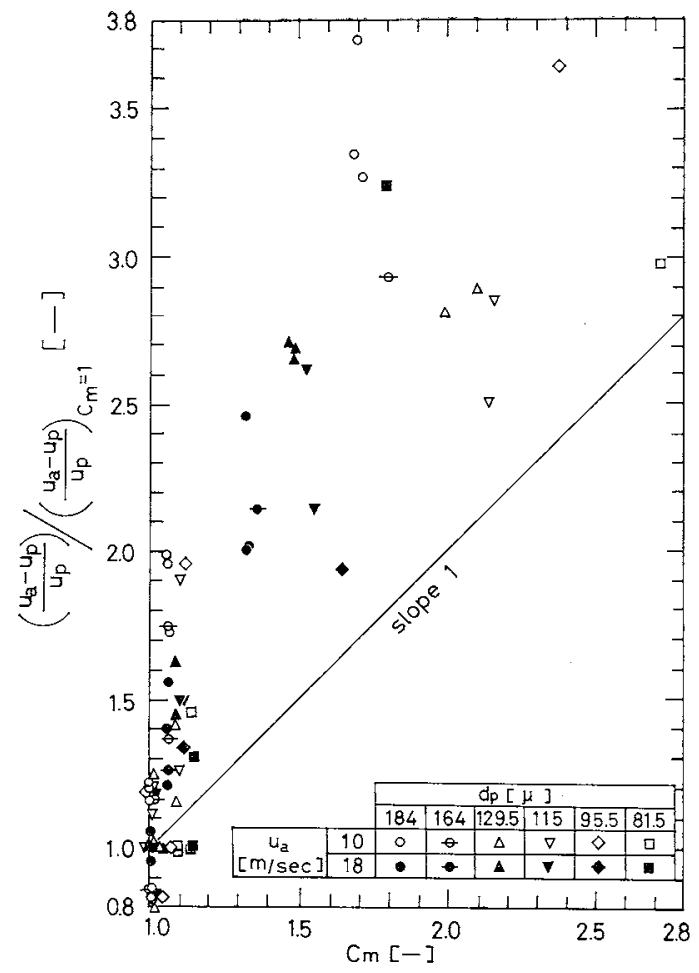

Fig. 8 Relation between $\left\{\left(\boldsymbol{u}_{a}-\boldsymbol{u}_{p}\right) / \boldsymbol{u}_{p}\right\} /\left\{\left(\boldsymbol{u}_{a}-\boldsymbol{u}_{p}\right) / \boldsymbol{u}_{p}\right\}_{C m=1}$ and $\mathrm{Cm}$

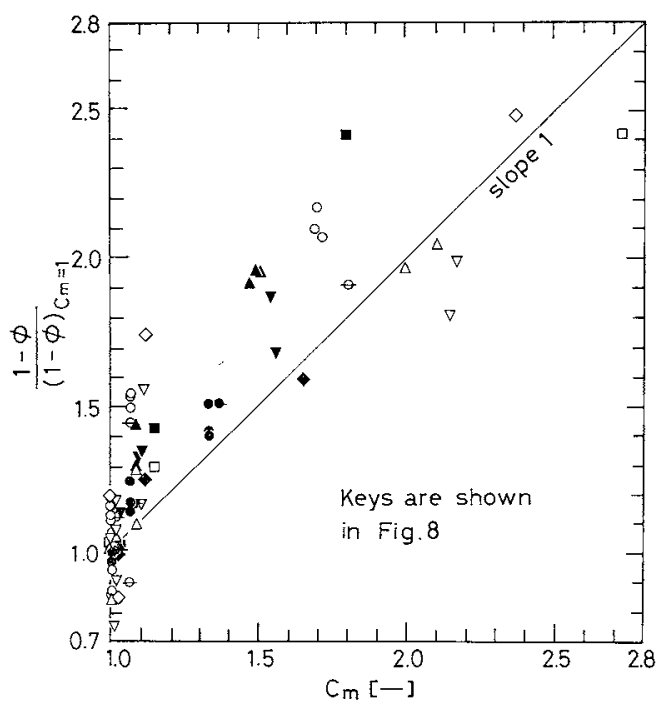

Fig. 9 Relation between $(1-\phi) /(1-\phi)_{C m=1}$ and $C m$

tween particles to particle diameter is estimated at from 400 to 1000 , and additional pressure drop was so small that it could not be measured. Therefore it can be considered that the concentration of particles was dilute and that treatment as single particle is reasonable. Also, since the gravitational term is neglected in horizontal pneumatic conveying, the equation of motion for a particle is given by: (refer to Appendix)

$$
\left(\frac{\pi}{6} d_{p}^{3} \rho_{p}\right) \frac{d u_{p}}{d t}=C_{D} C_{D}\left(\frac{\pi}{4} d_{p}^{2}\right) \frac{\rho_{a}\left(u_{a}-u_{p}\right)^{2}}{2}
$$

$$
-4 f_{p}\left(\frac{\pi}{6} \cdot d_{p}^{3} \rho_{p}\right) \frac{u_{p}^{2}}{2 D}
$$

Solving this equation for the Stokes region at steady state, we get

$$
u_{a}-u_{p}=C m\left(f_{p} \rho_{p} d_{p}^{2} u_{p}^{2} / 9 \mu_{a} D\right)
$$

There have been some reports on Fanning friction factor for particles, $f_{p}$, and many of them have shown that $f_{p}$ is inversely proportional to particle velocity (that is, $f_{p}=K / u_{p} K$ : constant) ${ }^{1,4,5)}$. From this relation Eq. (2) becomes

$$
\left(u_{a}-u_{p}\right) / u_{p}=C m\left(K \rho_{p} d_{p}^{2} / 9 \mu_{a} D\right)
$$

As $\rho_{p}, \mu_{a}$ and $D$ are constant in the present work, Eq. (3) suggests that $\left(u_{a}-u_{p}\right) / u_{p}$ is proportional to $\mathrm{Cm}$ under the condition of constant particle diameter. To examine the validity of this relation, Eq. (3) is rewritten as follows:

$$
\underset{u_{p}}{u_{a}-u_{p}} /\left(\begin{array}{c}
u_{a}-u_{p} \\
u_{p}
\end{array}\right)_{C m=1}=C m
$$

where the value of $\left[\left(u_{a}-u_{p}\right) / u_{p}\right]_{c m=1}$ was obtained by averaging the values at 50 and $100 \mathrm{mmHg}$ (at air velocity $10 \mathrm{~m} / \mathrm{sec}$ ) or $50 \mathrm{mmHg}$ only (at air velocity $18 \mathrm{~m} / \mathrm{sec}$ ), because of laminar flow and Stokes region under these conditions (see Fig. 4). The relation between $\left[\left(u_{a}-u_{p}\right) / u_{p}\right] /\left[\left(u_{a}-u_{p}\right) / u_{p}\right]_{C m=1}$ and $C m$ is plotted in Fig. 8. The data are apart from the straight line of slope unity and this correlation is not adequate. After several correlations were tried, it was found that $\left(u_{a}-u_{p}\right) /\left(u_{a}-u_{p}\right)_{C m=1}$ was proportional to $\mathrm{Cm}$. This correlation expressed by slip ratio is shown in Fig. 9. The data are scattered, but slip ratio is roughly proportional to the Cunningham correction coefficient.

\section{4 The effect of particle diameter and air velocity on} slip ratio

The slip ratio at air velocity $18 \mathrm{~m} / \mathrm{sec}$ is plotted against particle diameter in Fig. 10. The slip ratio increases with increasing particle diameter. The same inclination was also obtained at air velocity $10 \mathrm{~m} / \mathrm{sec}$, and it agrees qualitatively with that of previous works at atmospheric pressure. For the data in a range of pressures where flow in the duct was laminar and flow around the particle was in the Stokes region, $(1-\phi) / C m$ is plotted against $d_{p}$ in Fig. 11. In this figure it is found that in air velocities of both 10 and $18 \mathrm{~m} / \mathrm{sec}(1-\phi) / \mathrm{Cm}$ is independent of pressure and is proportional to $d_{p}$. The slip ratio at $10 \mathrm{~m} / \mathrm{sec}$ is greater than that at $18 \mathrm{~m} / \mathrm{sec}$. In previous works at atmospheric pressure, however, it has been reported that slip ratio is independent of air velocity or decreases with increasing air velocity.

From the slopes of the two straight lines in Fig. 11 the following equation is obtained.

$$
1-\phi=1.22 \mathrm{Cmd}_{p} u_{a}^{0.4}
$$

where $d_{p}[\mathrm{~cm}]$ and $u_{a}[\mathrm{~cm} / \mathrm{sec}]$. It should be noted 
that Eq. (5) is obtained in ranges of $K n_{p}, K n_{D}, R e_{p}$ and $R e_{D}$ at low pressure in Figs. 4 and 5 . Comparison of observed and calculated slip ratio from Eq. (5) is shown in Fig. 12. Most of the data are consistent with the correlation within $\pm 30 \%$.

From Eqs. (2) and (5) $f_{p}$ is given by

$$
f_{p}=\left(11.0 \mu_{a} D / \rho_{p}\right) u_{a}^{1.4} / d_{p} u_{p}^{2}
$$

This equation differs considerably from the equations for $f_{p}$ mentioned above. The reason for this discrepancy is not obvious, but it may be due to difference in the method of obtaining $f_{x}$. That is, in the previous works $f_{p}$ was calculated from additional pressure drop while in the present work it was calculated from slip velocity. Also, it may be due to the difference of flow regions previously discussed.

\section{Conclusion}

The velocity of glass beads entrained with air flow through a straight horizontal duct was measured in a range of pressures from 760 to $1 \mathrm{mmHg}$. As pressure was reduced, flow in the duct varied from turbulent to laminar and flow around the particle varied from Allen to Stokes region. It is found that the experimental conditions of the present work were considerably different from those of previous work, and that below $50 \mathrm{mmHg}$ the velocity slip on the particle surface (rarefaction effect) must be considered. The slip ratio $\left(u_{a}-u_{p}\right) / u_{a}$ obtained was proportional to the Cunningham correction coefficient, particle diameter and 0.4 power of air velocity. It was correlated within $\pm 30 \%$ by Eq. (5).

\section{Appendix}

According to the method of Weidner ${ }^{8)}$ the equation of motion for a particle group can be written as follows:

$$
\begin{aligned}
\left(G_{p} / u_{p}\right) d L\left(d u_{p} / d t\right)= & \left(C_{D}^{\prime} / C m\right) d A\left\{\rho_{a}\left(u_{a}-u_{p}\right)^{2} / 2\right\} \\
& -4 f_{p}(d L / D)\left(\rho_{d s} u_{p}^{2} / 2\right) D^{2}
\end{aligned}
$$

where

$$
\left(G_{p} / u_{p}\right) d L=d L \rho_{d s} D^{2}=n(\pi / 6) d_{p}^{3} \rho_{p}, d A=n(\pi / 4) d_{p}^{2}
$$

Also, since each particle is regarded as single particle

$$
C_{D}^{\prime}=C_{D}
$$

Substituting Eqs. (A-2) and (A-3) into Eq. (A-1), we get Eq. (1).

\section{Acknowledgment}

The authors thank Mr. K. Fukuyama for his cooperation in carrying out this work.

\section{Nomenclature}

$\begin{array}{ll}C_{D} & =\text { drag coefficient } \\ C m & =\text { Cunningham correction coefficient } \\ D & =\text { equivalent diameter of duct or pipe } \\ d_{p} & =\text { particle diameter } \\ d L & =\text { differential length of duct } \\ d A & =\text { sum of projected area of particles in duct } \\ & d L \text { in length } \\ f_{p} & =\end{array}$

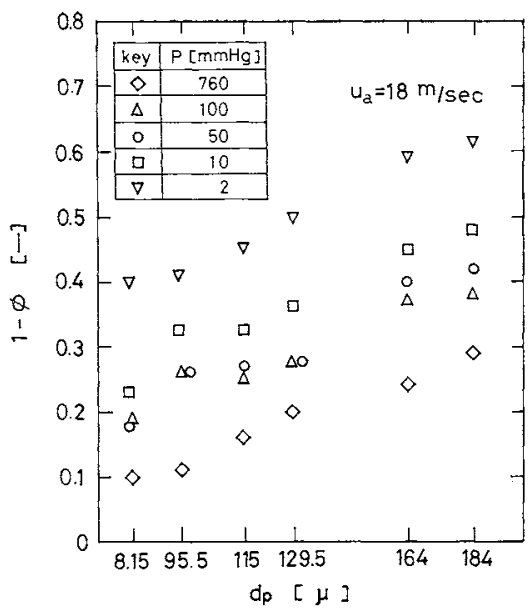

Fig. 10 Effect of particle diameter on slip ratio

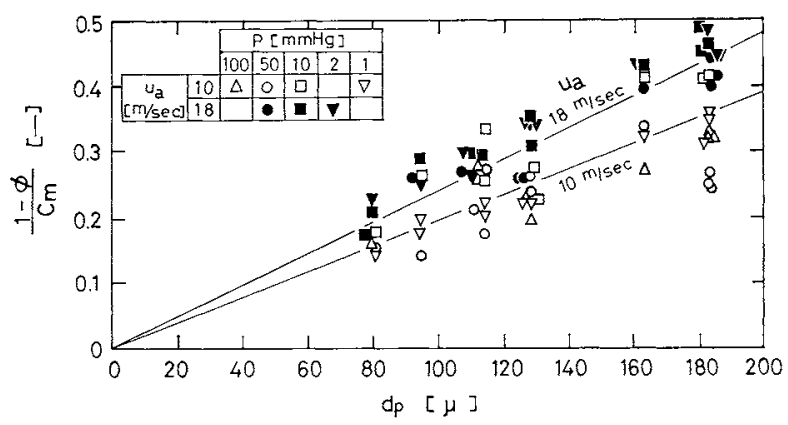

Fig. 11 Relations between $(1-\phi) / C m$ and $d_{p}$

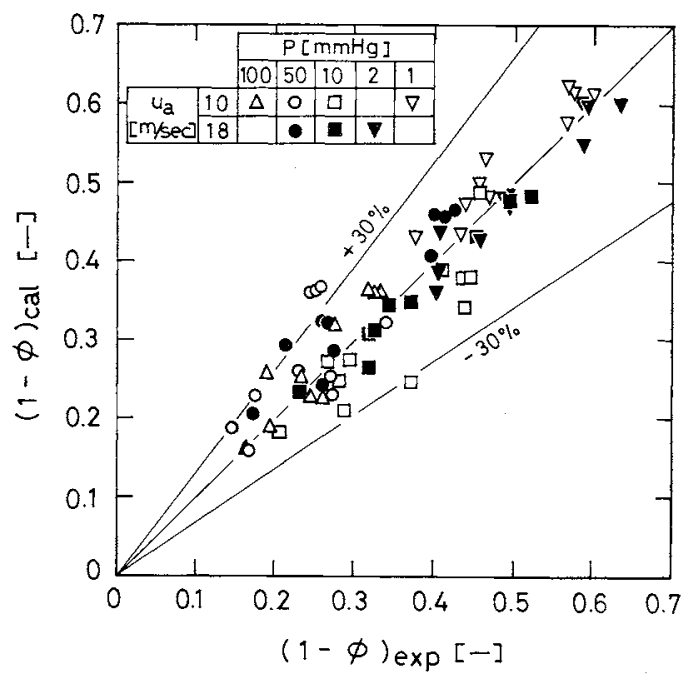

Fig. 12 Comparison of calculated and observed slip ratios

$G_{p} \quad=$ solid flow rate $\quad[\mathrm{g} / \mathrm{sec}]$

$g \quad=$ gravitational acceleration $\quad\left[\mathrm{cm} / \mathrm{sec}^{2}\right]$

$K \quad=$ constant $\quad[\mathrm{cm} / \mathrm{sec}]$

$K n_{D} \quad=$ duct Knudsen number $=\lambda / D$

$K n_{p} \quad=$ particle Knudsen number $=\lambda / d_{p}$

$n \quad=$ number of particles in duct $d L$ in length $\quad[-]$

$P \quad=$ pressure $\quad[\mathrm{mmHg}]$

$R e_{D} \quad=$ duct Reynolds number $=D u_{a_{j}} \rho_{a} / \mu_{a} \quad$ [-]

$R e_{p} \quad=$ particle Reynolds number $=d_{p}\left(u_{a}-u_{p}\right) \rho_{a} / \mu_{a}[--]$

$t \quad=$ time [sec]

$u_{a} \quad=$ average velocity of air for cross section $[\mathrm{cm} / \mathrm{sec}$ ]

$\begin{array}{lll}u_{p} & =\text { particle velocity } \quad[\mathrm{cm} / \mathrm{sec}]\end{array}$ 


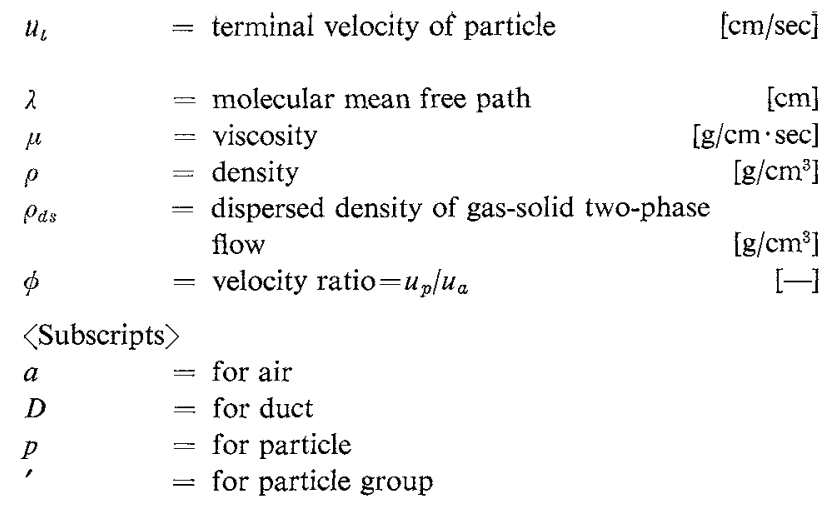

Literature Cited

1) Capes, C. E. and K. Nakamura: Can. J. Chem. Eng., 51, 31 (1973).

2) Gasterstädt, J.: Zeit des V. D. I., 68, 617 (1924).

3) Hinkle, B. L.: Ph. D. thesis, Geogia Inst. of Tech. (1953).

4) Konno, H., S. Saito and S. Maeda: Kagaku Kōgaku, 31, 243 (1967).

5) Konno, H. and S. Saito: J. Chem. Eng. Japan, 2, 211 (1969).

6) Munakata, T., Y. Seki, M. Mine and N. Hirai: Kagaku Kōgaku, 38, 675 (1974).

7) Munakata, T.: ibid., 38, 763 (1974).

8) Weidner, G.: Forschung, 21, 145 (1955).

(Presented in part at the 9th Autumn Meeting of The Soc. of Chem. Engrs., Japan, October 1975.)

\title{
THE ANALYSIS OF FLOW OF RAREFIED GASES THROUGH PACKED BEDS BY MONTE CARLO METHOD
}

\author{
Mitsuru SEZE, Yasuyuki NISHIMURA, Shuj SAKOHARA, \\ Hideo SHINAGAWA AND YUJI KAWAMURA \\ Department of Chemical Engineering, Hiroshima University, \\ Hiroshima 730
}

\begin{abstract}
The flow of rarefied gases through sphere packed beds under free molecular region was analyzed statistically by the Monte Carlo method. In analysis, the random packed beds were considered as a collective of regular packed units, and the permeability of this unit was calculated by the Monte Carlo method.

For extension to the packed bed, Oatley's method was used for the direction of flow and proportional allotment with the ratio of unit area to beds was adopted for the direction of cross section. The calculated results were in good agreement with observed values, suggesting that this analytical method affords easy calculation of conductance of packed beds.
\end{abstract}

\section{Introduction}

The study of transport phenomena under high vacuum conditions (Knudsen flow) is relatively easy in comparison with that in other cases. In this region, as intermolecular collisions are negligible, it is sufficient to consider only the behavior of each individual molecule. Thus, the statistical method is effective in analyzing transport phenomena. One of the methods which has been used most frequently with good results is the Monte Carlo method ${ }^{3,5}$.

With regard to transport phenomena under vacuum condition, Davis ${ }^{2\rangle}$ have made effective achievements in calculation of permeability in short tubes.

Received July 29, 1976. Correspondence concerning this article should be addressed to Y. Kawamura. M. Seze is at Idemitsu Kosan Co. Ltd., Himeji 672 and Y. Nishimura is at Babcock-Hitachi K. K., Kure 737.
In the analysis of the flow of gases through packed beds under high vacuum conditions, if the geometrical shape of the passage can be defined the behavior of each molecule can be simulated on the basis of kinetic theory using random numbers according to the Monte Carlo method. From many trials the macroscopic transfer parameter can be obtained by statistical accumulation.

In the present paper, the geometric shape of the passage in packed beds is described by using a regular packed unit of equal-size spheres. By applying the Monte Carlo method to one such model unit its permeability in the Knudsen region was calculated.

The conductance of a packed bed was calculated by regarding it as having been formed from several such units in series. 